\title{
Meteorological factors producing variation of tritium concentrations in Fukuoka, Japan
}

\author{
By H. Yokoyama ${ }^{1, *}$, S. Sugihara ${ }^{2}$ and N. Momoshima ${ }^{2}$ \\ ${ }^{1}$ Graduate school of Sciences, Kyushu University, Hakozaki Higashi-ku Fukuoka 812-8581, Japan \\ ${ }^{2}$ Radioisotope Center, Kyushu University, Hakozaki Higashi-ku Fukuoka 812-8581, Japan
}

(Received December 22, 2009; accepted in revised form December 20, 2010)

Summary. Tritium concentrations of rain and river water in Fukuoka, Japan were determined by in combination of electrolytic enrichment of tritium and liquid scintillation counting. A cyclic seasonal variation is observed for tritium concentration in rain: high in winter/spring and low in summer/autumn. The detailed examination of the seasonal variation using the back trajectory analysis suggests that rain clouds arrived at Fukuoka from the Eurasia continent have higher tritium concentration than those from the Pacific Ocean. The seasonal change is concluded to be determined by migration pathway which is strongly dependent upon meteorological factors in Fukuoka. The river water of Tatara River has lower tritium concentration than rain and does not show a cyclic variation observed on rain, showing smoother change than rain, which indicates continuous supply of groundwater contained old rain to the river water. The difference of tritium concentrations between river water and rain suggest that the residence time of the groundwater should be longer than 6.8 years.

\section{Introduction}

Tritium is a radioactive isotope of hydrogen with 12.32 years half-life and is produced naturally in the upper atmosphere by interaction with secondary cosmic radiation. Tritium, in the form of HTO, has been incorporated into a hydrological cycle and has been used as a tracer of water movement for many years. Nuclear power reactors are source of tritium in the environment. The typical tritium discharge rates in liquid effluent are estimated to be $2.90 \times 10^{5} \mathrm{GBq} \mathrm{GW}^{-1} \mathrm{a}^{-1}$ from heavy water reactor, $0.27 \times 10^{5} \mathrm{GBq} \mathrm{GW}^{-1} \mathrm{a}^{-1}$ from pressurized water reactor and $0.021 \times 10^{5} \mathrm{GBq} \mathrm{GW}^{-1} \mathrm{a}^{-1}$ from boiling water reactor. In airborne effluents, discharged rates are estimated to be $6.70 \times 10^{5} \mathrm{GBq} \mathrm{GW}^{-1} \mathrm{a}^{-1}$ from heavy water reactor, $0.059 \times 10^{5} \mathrm{GBq} \mathrm{GW}^{-1} \mathrm{a}^{-1}$ from pressurized water reactor and $0.034 \times 10^{5} \mathrm{GBq} \mathrm{GW}^{-1} \mathrm{a}^{-1}$ from boiling water reactor [1]. At present 432 nuclear power reactors are under operation in the world and $390,44 \mathrm{GW}$ of the electricity is produce. In addition to the present nuclear power plants, a large quantity of tritium will be used as a fuel at nuclear fusion reactor in future that would be a potential source of environmental tritium.

As shown in Fig. 1, Japan is located at the eastern edge in Eurasia continent and covered with air mass mostly from

*Author for correspondence

(E-mail: 2sc09055g@s.kyushu-u.ac.jp).

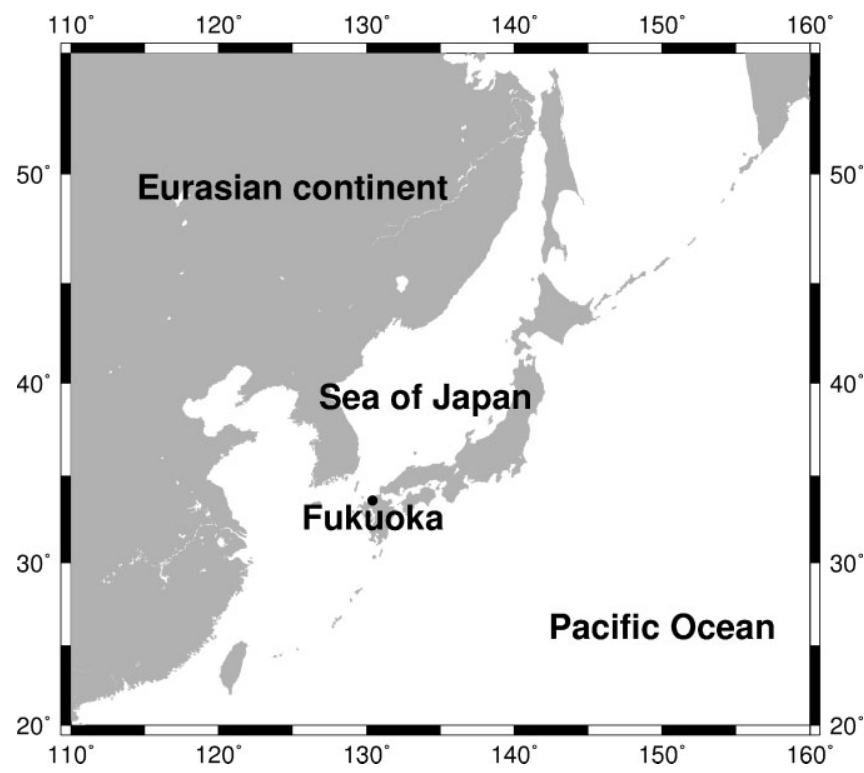

Fig. 1. Sampling location.

the Pacific Ocean in summer and that mostly from the Eurasia continent in winter. Fukuoka is situated in western region of Japan and close to the Eurasia continent, and then the city is characterized with the meteorological features such as strong wind from west in winter compared to other cities facing the Pacific Ocean.

We have measured tritium concentrations of environmental waters; rain and river in Fukuoka for these 5 years. In this paper, we discuss meteorological factors responsible for variation of tritium concentration in rain and that of small river water system in Fukuoka.

\section{Experimental}

Each rain water sample was collected with a plastic tray placed on a roof of a building at Kyushu University, Fukuoka for the period from May 2005 to April 2009 and pH was measured for samples after Mar, 2008 (CyberScan pH 300, Eutech Instruments). River water samples were collected at two points (upper and middle) along the Tatara River every month for the period from April 2007 to March 2009. The distance of the sampling points is about $6 \mathrm{~km}$ and the 
catchment area of the Tatara River system is $173.2 \mathrm{~km}^{2}$. The water samples were distilled two times and electrolyzed using a commercially available tritium enrichment system equipped with solid polymer electrolyte (Tripure XZ001, PERMELEC ELECTRODE LTD.). About 8 times enrichment of tritium concentration is possible by volume reduction from $1000 \mathrm{ml}$ to $80 \mathrm{ml}$ of a final volume. After enrichment, $50 \mathrm{ml}$ portion of the enrich water was mixed with $50 \mathrm{ml}$ of scintillation cocktail (Ultima Gold LLT, PERKINELMER) in a $120 \mathrm{ml}$ Teflon vial and tritium activity was measured with a low background liquid scintillation counter (LSC-LB5, ALOKA) for $1200 \mathrm{~min}$ for each sample. An external standard channel ratio (ESCR) method was applied to quenching correction of each sample to determine counting efficiency. The detection limit of $0.030 \mathrm{~Bq} \mathrm{~L}^{-1}$ is achieved for enriched water samples.

\section{Result and discussion}

\subsection{Tritium concentrations in rain}

The tritium concentrations in rain are shown in Fig. 2, vary between 0.23 and $2.07 \mathrm{BqL}^{-1}$ with an average of $0.79 \pm$ $0.26 \mathrm{BqL}^{-1}(n=93)$. Tritium concentrations were clearly lower than those measured early 1980s at Fukuoka, which still remained slight influence from atmospheric nuclear test [2]. A cyclic seasonal change is clearly observed as shown in Fig. 2, an increase in winter/spring and a decrease in summer/autumn. The seasonal average tritium concentrations are calculated for spring (March-May), summer (June-August), autumn (September-November), and winter (December-February), and are summarized in Table 1.

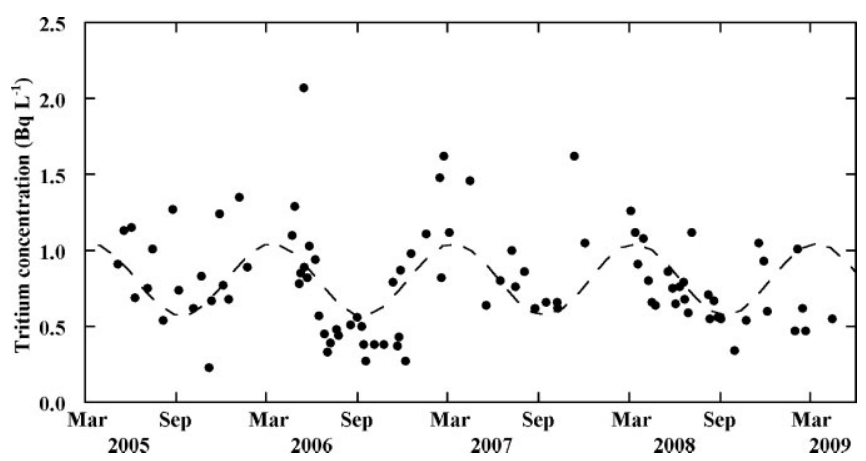

Fig. 2. Variation of tritium concentrations in rain. The broken line shows a sine curve fitting with one year cycle.

Table 1. The average tritium concentration with seasons.

\begin{tabular}{lcccc}
\hline & \multicolumn{4}{c}{ Tritium concentration $\left(\mathrm{Bq} \mathrm{L}^{-1}\right)$} \\
\cline { 2 - 5 } & Spring & Summer & Autumn & Winter \\
\hline 2005 & 1.02 & 0.90 & 0.72 & 0.92 \\
2006 & 1.10 & 0.52 & 0.49 & 1.05 \\
2007 & 1.07 & 0.81 & 0.89 & 1.05 \\
2008 & 0.90 & 0.71 & 0.68 & 0.63 \\
av & 1.01 & 0.71 & 0.65 & 0.89 \\
\hline av & Winter/Spring & 0.96 & & \\
av & Summer/Autumn & 0.68 & & \\
\hline
\end{tabular}

The maximum difference of tritium concentrations between highest season and lowest one is $0.26-0.63 \mathrm{~Bq} \mathrm{~L}^{-1}$ in $2005-$ 2009.

\subsection{The back trajectory analysis}

Back trajectory analysis was carried out to elucidate factors responsible to the seasonal variation observed for these 5 years in rain samples. Back trajectory calculations were performed using the Global Meteorological Data Display System (GMET) opened by the Center for Global Environment Research (CGER), National Institute for Global Environmental Studies (NIES). The system uses the meteorological datasets supplied by the National Centers for Environmental Prediction. The calculation was started from the mid time of each rain event and back to $168 \mathrm{~h}$ before. The latitude, longitude, and altitude of air mass every $1 \mathrm{~h}$ was calculated.

The back trajectory calculated for the rain in Nov 2008 is shown in Fig. 3 as an example, the trajectory back to the Arctic Ocean and moved to Fukuoka passing through the Eurasia continent. The back-trajectory of each rain sample calculated is classified into 8 directions by the way and movement speed a few days before the rain cloud came to Fukuoka. The proportion and average tritium concentrations of rain for 8 directions are summarized in Table 2. The rain cloud came from $\mathrm{W} / \mathrm{NW}$ had higher tritium concentrations than other directions. The results suggest that the tritium concentrations of rain cloud that arrived at Fukuoka from the Eurasia continent (north-northwest) have higher tritium concentration than that from the Pacific Ocean (east-southeast). It is reported that tritium concentration of water vapor of continental air mass is higher than that of oceanic air mass, because a large dilution of tritium concentration occurs in oceanic area by water vapor evaporated from seawater which

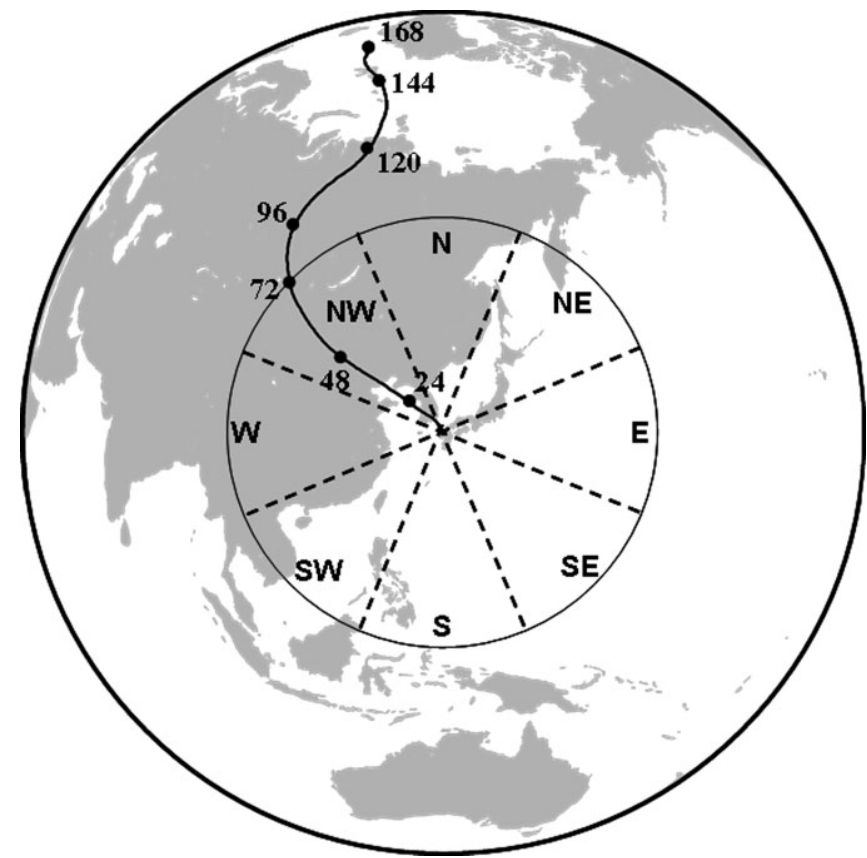

Fig. 3. The back trajectory analysis of rain in November 2008 $\left(1.08 \mathrm{BqL}^{-1}\right)$. The solid line from Fukuoka shows $168 \mathrm{~h}$ back trajectory. 
Table 2. The average tritium concentrations of rain for each direction.

\begin{tabular}{lcc}
\hline Direction & $\begin{array}{c}\text { Average conc. } \\
\left(\mathrm{BqL}^{-1}\right)\end{array}$ & $\begin{array}{c}\text { Proportion } \\
(\%)\end{array}$ \\
\hline $\mathrm{N}$ & & 0 \\
$\mathrm{NE}$ & & 0 \\
$\mathrm{E}$ & 0.47 & 6 \\
$\mathrm{SE}$ & 0.51 & 10 \\
$\mathrm{~S}$ & 0.59 & 18 \\
SW & 0.74 & 25 \\
$\mathrm{~W}$ & 0.94 & 27 \\
$\mathrm{NW}$ & 1.19 & 14 \\
& 0.79 & 100 \\
\hline
\end{tabular}

has low tritium concentration [3]. The high tritium concentration in continental area than oceanic area is attributed to the slower dilution of tritium, both natural and nuclear test origins owing to less contact with water vapor from seawater. The seasonal variation of tritium concentration in rain seems to be determined by migration pathway of each rain cloud, which is closely related to meteorological situation at Fukuoka.

\subsection{Relationship between $\mathrm{pH}$ and tritium concentration in rain}

The relation between $\mathrm{pH}$ and tritium concentration is shown in Fig. $4(n=28)$. There is a tendency that a slight raise of the tritium concentration with decreasing the $\mathrm{pH}$ value. The rains categorized to $\mathrm{S}, \mathrm{SE}$ and $\mathrm{E}$ has lower tritium concentration with higher $\mathrm{pH}$ value than that categorized to $\mathrm{NW}, \mathrm{W}$ and SW.

A long range transport of pollutants from China to Japan is reported [4-6] and larger influence has observed on the areas in Japan facing to the Sea of Japan, especially in winter season due to strong westerly wind. The increase in ion concentrations (non-sea-salt $\mathrm{SO}_{4}{ }^{2-}$, non-sea-salt $\mathrm{Ca}^{2+}, \mathrm{H}^{+}$) by pollutant has been observed in winter at Fukuoka when air mass comes from Eurasia continent [7]. The low $\mathrm{pH}$ value of rains from north-northeast shown in Fig. 3 is concluded to be resulted from pollutants contaminated in China.

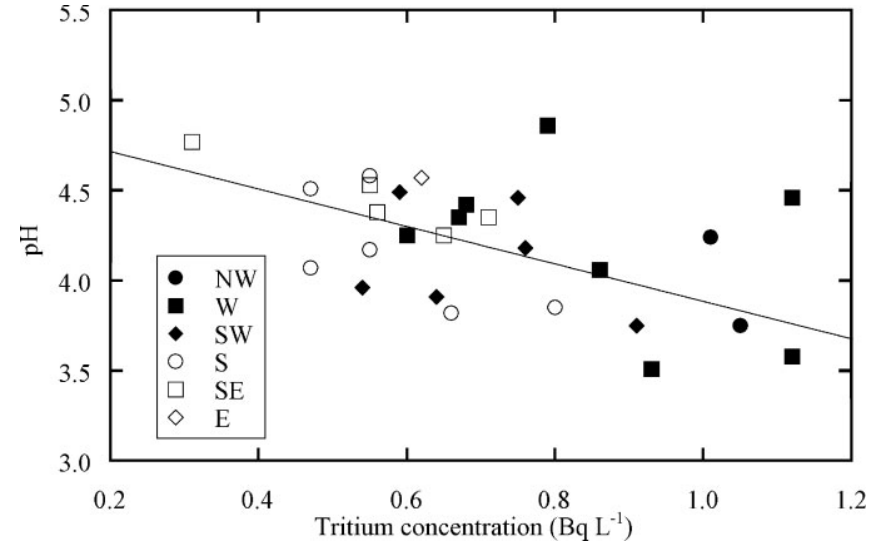

Fig. 4. Relation between $\mathrm{pH}$ and tritium concentration in rain sample.

\subsection{Tritium concentration in river}

Tritium concentration of a small river system would reflect that of rain easier than that of larger river system because of small catchment and small underground reservoir. The degree of reflection of rain would depend on a residence time of groundwater that mixed into river water and fraction of rain occupied in river water. The tritium concentrations in the river system of Tatara River are shown in Fig. 5 together with tritium concentration of rain and rainfall. The tritium concentration of Tatara River water varied between 0.39 and $0.83 \mathrm{~Bq} \mathrm{~L}^{-1}$ from April 2007 to April 2009 and shows an average of $0.54 \pm 0.09 \mathrm{~Bq} \mathrm{~L}^{-1}(n=48)$, while that of rain varied between 0.31 and $1.62 \mathrm{~Bq} \mathrm{~L}^{-1}$ with an average of $0.79 \pm 0.21 \mathrm{~Bq} \mathrm{~L}^{-1}$ for the same period. The dotted line in the figure is the estimated cyclic variation of tritium concentration of rain shown in Fig. 2. The difference of the average tritium concentrations between river and rain is $0.25 \mathrm{~Bq} \mathrm{~L}^{-1}$.

The difference in tritium concentration of river water and rain is similar to that observed on rain between winter/spring and summer/autumn as shown in Table 2. However, the seasonal variation is not the cause for the difference of tritium concentration of river water and rain because the tritium concentration of river water is obviously lower than that of rain. This indicates that groundwater

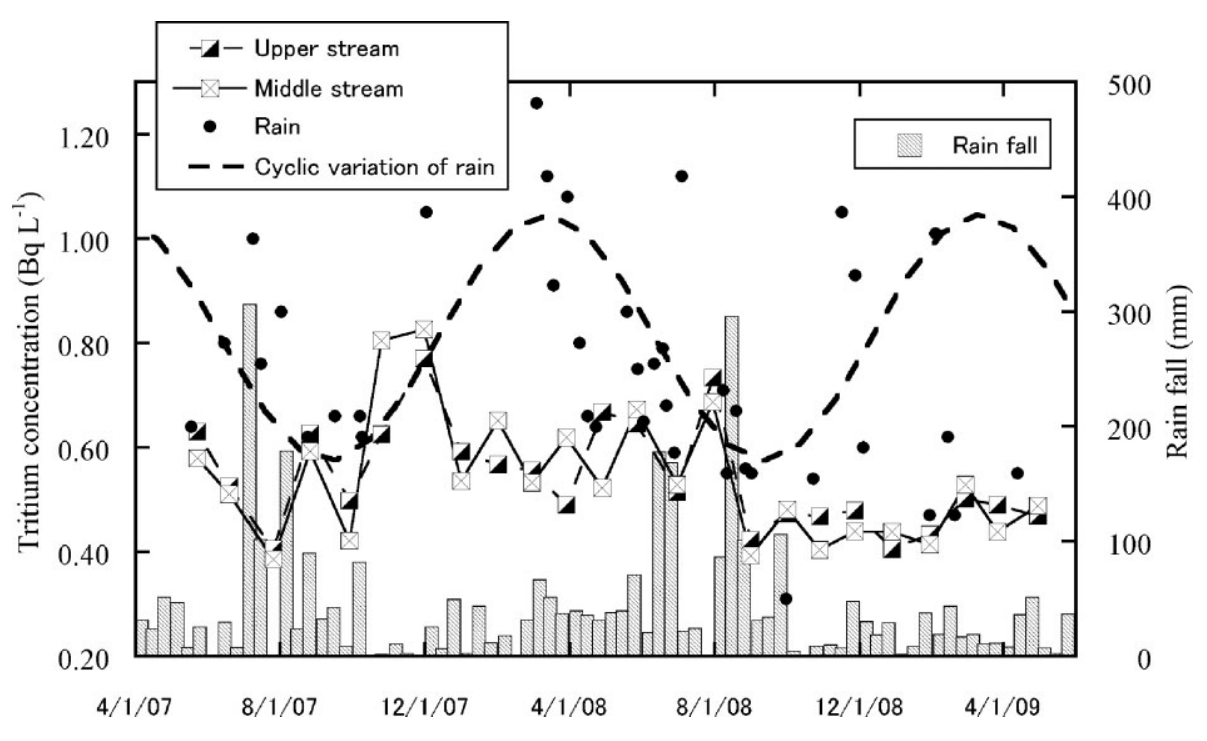

Fig. 5. Tritium concentration in river (upper and middle stream) and rainfall in Fukuoka city. 
with low tritium concentration is supplied to the area of Tatara River where the water samples were taken because no significant difference was observed for upper and middle stream sampling points. It is clear that the variation of tritium concentration in rain is not reflected on the river water, more flat and smooth compared to than rain. The decay time of 6.8 years is expected to decrease the average tritium concentration of rain to that of river water. The underground reservoir usually consists of mixtures of rain for some period and river water also contains recent rains which have kept on surface soil layers for very short period. The estimated decay time is a minimum value of residence time of groundwater supplied to the Tatara River. The actual residence time should be longer than 6.8 years.

\section{Conclusion}

Tritium concentrations of rain and river water in Fukuoka, Japan were measured and a seasonal variation is observed in rain, high in winter/spring and low in summer/autumn. The back trajectory analysis proved that the cause of the seasonal variation is the migration pathways of rain cloud arrive at Fukuoka which comes mostly from the west/north in winter and from south/east in summer. The higher tritium concentration circumstance in the continental area and than the Pacific Ocean is well reflected on rain in Fukuoka. The river water in Tatara River at Fukuoka has lower tritium concentration than rain and does not show any cyclic variation in tritium concentration that observed in rain. It suggests that groundwater with residence time longer than 6.8 years is supplied to the Tatara River.

Acknowledgment. The work is performed with the support and under the auspices of the NIFS Collaborative Research Program (NIFS04KOBS008, NIFS07KOBS011).

\section{References}

1. United Nation Scientific Committee in the Effects of Atomic Radiation: Sources, Effects and Risks of Ionizing Radiation, UNSCEAR 1988 report to the General Assembly, with Scientific Annexes (1988).

2. Momoshima, N., Hayashi, Y.: Meteorologically induced seasonal variation of tritium concentrations in rain at Fukuoka, Japan, LSC2001, Advance in Liquid Scintillation Spectrometry. Radiocarbon, The University of Arizona (2002), p. 181.

3. Matsuoka, N., Hirai, E., Tagomori, H., Momoshima, N., Takashima, Y., Meteorological analysis of tritium concentrations in rain water collected in Fukuoka, Japan, from 1987-1991. Sci. Total Environ. 145, 197 (1994).

4. Kitamura, M., Sugiyama, M., Ohhashi, T., Nakai, N.: An estimation of the origin of sulfate ion in rain water in view of sulfur isotopic variations. Chikyukagaku 27, 109 (1993).

5. Ohizumi, T., Fukuzaki, N., Kusakabe, M.: Sulfur isotopic view on the sources of sulfur in atmospheric fallout along the coast of the sea of Japan. Atmos. Environ. 31, 1339 (1997).

6. Yanagisawa, F., Ueda, A., Shida, J.: Sources of sulfate in wet deposits in Yonezawa, Yamagata Prefecture, Japan. Bunseki Kagaku 43, 947 (1994).

7. Momoshima, N., Sugihara, S., Toyoshima, T., Nagao, Y., Takahashi, M., Nakamura, Y.: Seasonal Variability of tritium and ion concentrations in rain at Kumamoto, Japan and back-trajectory analysis of air mass. Fusion Sci. Tech. 54, 293 (2008). 